\title{
Real-Time Noise Measurement in Supercontinuum Generation in PM and Non-PM ANDi Tellurite Fibers
}

Rao, Shreesha D. S.; Karpate, Tanvi; Ghosh, Amar Nath; Klimczak, Mariusz; Pysz, Dariusz; Buczynski, Ryszard; Billet, Cyril; Bang, Ole; Dudley, John M.; Sylvestre, Thibaut

\section{Published in:}

Proceedings of 2020 Conference on Lasers and Electro-Optics

Link to article, DOI:

10.1364/CLEO_SI.2020.STh3P.4

Publication date:

2020

Document Version

Peer reviewed version

Link back to DTU Orbit

Citation (APA):

Rao, S. D. S., Karpate, T., Ghosh, A. N., Klimczak, M., Pysz, D., Buczynski, R., Billet, C., Bang, O., Dudley, J. M., \& Sylvestre, T. (2020). Real-Time Noise Measurement in Supercontinuum Generation in PM and Non-PM ANDi Tellurite Fibers. In Proceedings of 2020 Conference on Lasers and Electro-Optics [9193151] IEEE. https://doi.org/10.1364/CLEO_SI.2020.STh3P.4

\section{General rights}

Copyright and moral rights for the publications made accessible in the public portal are retained by the authors and/or other copyright owners and it is a condition of accessing publications that users recognise and abide by the legal requirements associated with these rights.

- Users may download and print one copy of any publication from the public portal for the purpose of private study or research.

- You may not further distribute the material or use it for any profit-making activity or commercial gain

- You may freely distribute the URL identifying the publication in the public portal 


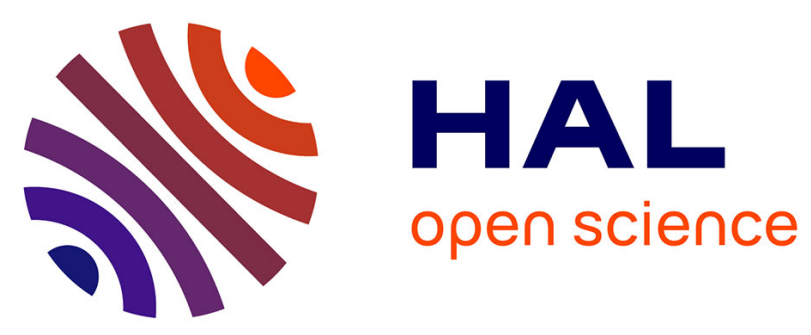

\section{Real-time noise measurement in supercontinuum generation in PM and non-PM ANDi tellurite fibers}

Shreesha Rao Delanthabettu Shivarama, Tanvi Karpate, Amar Nath Ghosh,

Mariusz Klimczak, Dariusz Pysz, Ryszard Buczyński, Cyril Billet, Ole Bang, John Michaël Dudley, Thibaut Sylvestre

\section{To cite this version:}

Shreesha Rao Delanthabettu Shivarama, Tanvi Karpate, Amar Nath Ghosh, Mariusz Klimczak, Dariusz Pysz, et al.. Real-time noise measurement in supercontinuum generation in PM and non-PM ANDi tellurite fibers. Conference on Lasers and Electro-Optics, May 2020, Washington, United States. hal-03368996

\section{HAL Id: hal-03368996 \\ https://hal.archives-ouvertes.fr/hal-03368996}

Submitted on 7 Oct 2021

HAL is a multi-disciplinary open access archive for the deposit and dissemination of scientific research documents, whether they are published or not. The documents may come from teaching and research institutions in France or abroad, or from public or private research centers.
L'archive ouverte pluridisciplinaire HAL, est destinée au dépôt et à la diffusion de documents scientifiques de niveau recherche, publiés ou non, émanant des établissements d'enseignement et de recherche français ou étrangers, des laboratoires publics ou privés. 


\title{
Real-time noise measurement in supercontinuum generation in PM and non-PM ANDi tellurite fibers
}

\author{
Shreesha Rao D. S. ${ }^{1}$, Tanvi Karpate 2,3,", Amar Nath Ghosh ${ }^{4}$, Mariusz Klimczak ${ }^{2,3}$, Dariusz Pysz ${ }^{2}$, Ryszard \\ Buczynski $^{2,3}$, Cyril Billet ${ }^{4}$, Ole Bang ${ }^{1,5}$, John M. Dudley ${ }^{4}$, and Thibaut Sylvestre ${ }^{4}$ \\ ${ }^{I}$ DTU Fotonik, Department of Photonics Engineering, Technical University of Denmark, Ørsteds Plads, 2800 Kongens Lyngby, Denmark. \\ ${ }^{2}$ Institute of Electronic Materials Technology, Wólczynska 133, 01-919 Warsaw, Poland \\ ${ }^{3}$ University of Warsaw, Faculty of Physics, Pasteura 7, 02-093 Warsaw, Poland \\ ${ }^{4}$ Institut FEMTO-ST, CNRS, UMR 6174, Université Bourgogne Franche-Comté, Besançon, France \\ ${ }^{5}$ NKT Photonics A/S, Blokken 84, 3460 Birkerød, Denmark. \\ Corresponding author: tanvi.karpate@itme.edu.pl
}

\begin{abstract}
We compare real-time noise measured using dispersive Fourier transform spectroscopy in supercontinuum generated in PM and non-PM all-normal dispersion tellurite fibers and show that PM fiber provides better stability and higher coherence. (C) 2020 The Author(s)
\end{abstract}

Supercontinuum (SC) generation in all-normal dispersion (ANDi) fibers is usually characterized by a high degree of coherence and a low relative intensity noise (RIN) as compared to that in anomalous dispersion fibers [1]. However, it has recently been established that SC coherence in ANDi fibers degrades with increase in pulse duration and fiber length due to parametric interaction between coherent and incoherent components [2]. Futhermore, Gonzalo et al. [3] recently showed that polarization modulational instability (PMI) introduces a power-dependent coherence degradation in ANDi fibers, which cannot be reproduced using a scalar single-polarization model of SC generation. Recently, a robust, all-fiber pump oscillator and ANDi SC source has been demonstrated in an all-polarization maintaining (PM) architecture [4]. When a PM ANDi fiber with suitable pump parameters and fiber length is used to avoid PMI, it was shown that technical noise from the pump strongly dominates quantum noise and becomes essential in determining the SC noise [5,6].

In this work, we directly compare, using real-time dispersive Fourier transformation (DFT) technique, the SC generated in PM-ANDi and non-PM ANDi fibers made from highly nonlinear tellurite glass. The fibers used in the experiment were in-house fabricated, hexagonal lattice photonic crystal fibers (PCFs) with seven rings of air-holes surrounding the core. The dimensions of the lattice were engineered to obtain all-normal dispersion profiles. A fiber with birefringence introduced by two increased-diameter holes inside the lattice adjacent to the core was fabricated as the PM PCF variant. We pumped the PCFs with an optical parametric oscillator with pulse duration of $200 \mathrm{fs}$ centered at $1550 \mathrm{~nm}, 80 \mathrm{MHz}$ repetition rate. The SC generated from the fibers was first recorded using an optical spectrum analyzer (OSA). The signal from the fiber was then time stretched in a $170 \mathrm{~m}$ dispersion compensating fiber (DCF) with dispersion, $\mathrm{D}=-83.89 \mathrm{ps} / \mathrm{nm} . \mathrm{km}$ at $1550 \mathrm{~nm}$. The stretched pulse was recorded with a $50 \mathrm{GHz}-$ bandwidth photodiode and observed on an oscilloscope with a $12 \mathrm{GHz}$ bandwidth. Total number of pulses recorded in one reading was 400 corresponding to $5 \mu$ s time duration. Along with this, the full SC spectra were recorded with an Ocean Optics NIRquest spectrometer. Average pump power input in the PCFs was $250 \mathrm{~mW}$. For the PM fiber, its principal axis was determined and readings were taken at the two orthogonal polarizations as well as at an offset of $45^{\circ}$ between the two modes.

We observed a very drastic difference in the noise properties of the SC generated in non-PM and PM ANDi fibers. The noise in non-PM fiber was high, which possibly indicates the detrimental role of polarization modulational instability (PMI) in SC generation. This provides experimental evidence that for similar pump parameters and fiber lengths, the PM fibers enable coherent SC generation with lower intensity noise, than their nonPM variants, which can be beneficial for various applications such as optical coherence tomography and confocal microscopy.

Dispersion-compensated time stretching allows us to observe the "spectrum" of the pulse, whose intensity essentially mimics that of the frequency spectrum due to large linear stretching of the temporal pulse which leads to separation of the individual wavelengths whose intensity profile is similar to that of the frequency spectrum. The conditions for conversion from oscilloscope time-base to wavelength spectrum in DFT are 1) a known chromatic dispersion characteristic of the stretching element (DCF fiber in our case) and, 2) linear (dispersive only) propagation over the stretching DCF fiber. This was assured in our work by limiting the SC power at the DCF input and by monitoring the SC spectrum before and after the DCF fiber. DFT method is advantageous as it allows us to measure RIN across a range of wavelengths in one measurement, without having to adjust filter, thus consequently increasing the accuracy of measurements. Fig. 1 shows accurate mapping of the oscilloscope time-base into the wavelength scale as obtained by DFT for non-PM and PM fiber. The mismatch between the OSA-measured 
spectrum and the DFT-retrieved spectrum for the non-PM fiber is attributed to $\mathrm{OH}^{-}$absorption over the significant length of the DCF stretcher used in the experiment.
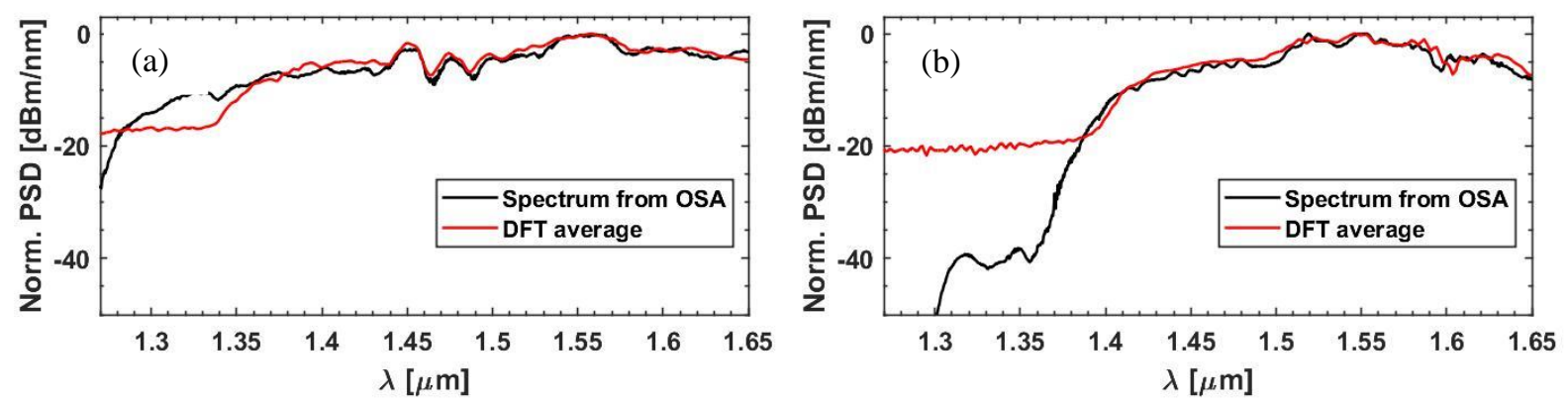

Fig. 1 Overlapping spectra from OSA (black) and the DFT spectra (red) for non-PM (a) and PM fiber (b)

Experimental results show intensity fluctuations in SC generated in ANDi PCFs with the length of $12.6 \mathrm{~cm}$. Fig. 2 shows shot-to-shot measurements of 400 realizations from DFT spectroscopy. We limit our investigation of the spectral noise to a wavelength range of 1.3-1.65 $\mu \mathrm{m}$ due to technical limitation of the photodiode and the DCF. The real-time fluctuations are shown in grey while red depicts the mean of these real-time spectra. It can be inferred from these measurements that the PM fiber has lower noise fluctuation compared to non-PM fiber. These results are promising and motivate further study, e.g. using the interferometry variant of DFT in order to assess the coherence property of SC generated in both variants of PCFs.
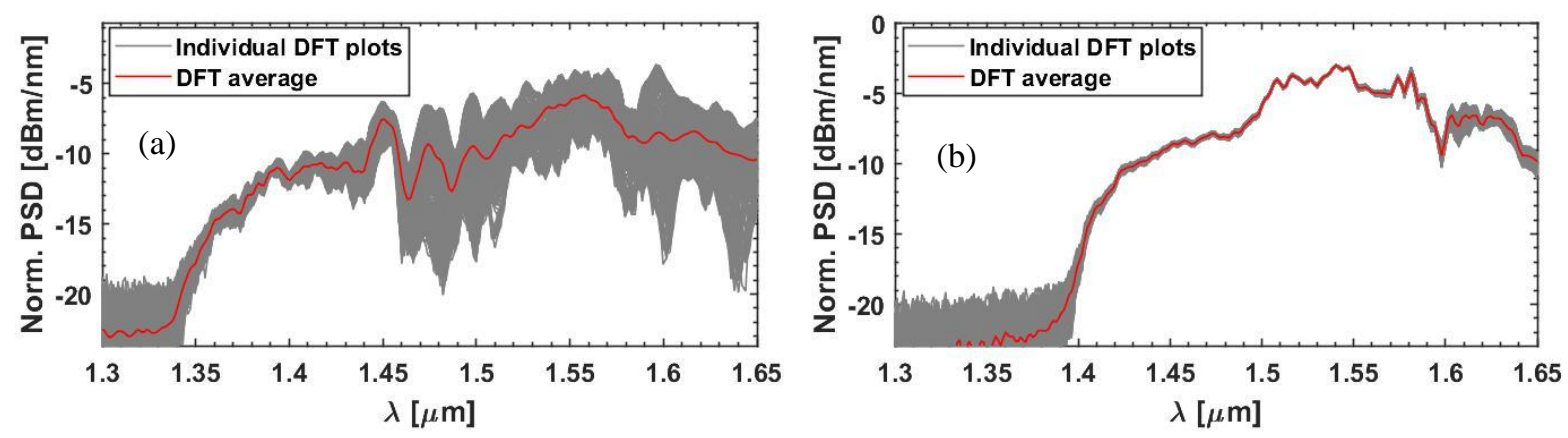

Fig. 2. Shot-to-shot real-time fluctuations of 400 realisations (grey) and the mean spectra (red) for (a) non-PM and (b) PM fibers

In conclusion, we reported first DFT-based real-time noise comparison in SC generation in PM and non-PM ANDi PCFs. We show that SC generation in PM fiber has higher stability and lower noise as compared to the its non-PM variant. This is an indirect evidence that PMI contributes to coherence degradation and consequently, increase in noise, in SC generation.

Funding: Horizon 2020 Framework Programme Marie Curie grant No. (722380 [SUPUVIR]); Fundacja na rzecz Nauki Polskiej (FNP) (First TEAM/2016-1/1 - POIR.04.04.00-00-1D64/16-00)

[1] M. Klimczak, G. Soboń, R. Kasztelanic, K. M. Abramski, and R. Buczyński, "Direct comparison of shot-to-shot noise performance of all normal dispersion and anomalous dispersion supercontinuum pumped with sub-picosecond pulse fiber-based laser," Sci. Rep., vol. 6, no. December 2015, pp. 1-14, 2016.

[2] A. M. Heidt, J. S. Feehan, J. H. V. Price, and T. Feurer, "Limits of coherent supercontinuum generation in normal dispersion fibers," $J$. Opt. Soc. Am. B, vol. 34, no. 4, p. 764, Apr. 2017.

[3] I. B. Gonzalo, R. D. Engelsholm, M. P. Sørensen, and O. Bang, "Polarization noise places severe constraints on coherence of allnormal dispersion femtosecond supercontinuum generation," Sci. Rep., vol. 8, no. 1, pp. 1-13, 2018.

[4] K. Tarnowski, T. Martynkien, P. Mergo, J. Sotor, and G. Soboń, "Compact all-fiber source of coherent linearly polarized octavespanning supercontinuum based on normal dispersion silica fiber," Sci. Rep., vol. 9, no. 1, pp. 1-8, 2019.

[5] S. Rao D. S., et al. "Ultra-low-noise supercontinuum generation with a flat near-zero normal dispersion fiber." Opt. let. vol. 44 no. 9 pp. 2216-2219, 2019.

[6] E. Genier, P. Bowen, T. Sylvestre, J. M. Dudley, P. Moselund, and O. Bang, "Amplitude noise and coherence degradation of femtosecond supercontinuum generation in all-normal-dispersion fibers," J. Opt. Soc. Am. B, vol. 36, no. 2, p. A161, Feb. 2019. 